\title{
Modelling and optimization of ethyl butyrate production catalysed by Rhizopus oryzae lipase
}

\author{
C. Grosso ${ }^{\text {a }}$, S. Ferreira-Dias ${ }^{\mathrm{b}}$, P. Pires-Cabral ${ }^{\mathrm{a}, \mathrm{b}, *}$ \\ a Instituto Superior de Engenharia, Universidade do Algarve, Campus da Penha, 8005-139 Faro, Portugal \\ ${ }^{\mathrm{b}}$ Instituto Superior de Agronomia, CEER-Biosystems Engineering, Technical University of Lisbon, Tapada da Ajuda, 1349-017 Lisboa, Portugal
}

\section{A R T I C L E I N F O}

\section{Article history:}

Available online 13 August 2012

\section{Keywords:}

Ethyl butyrate

Immobilised lipase

Rhizopus oryzae

Modelling

Optimisation

Polyurethane foam

\begin{abstract}
A B S T R A C T
Response surface methodology was used to model and optimise the production of ethyl butyrate, catalysed by Rhizopus oryzae lipase immobilised in a hydrophilic polyurethane foam. Experiments were carried out following a central composite rotatable design, as a function of reaction temperature ( $T$ : $\left.22-38{ }^{\circ} \mathrm{C}\right)$ initial butyric acid concentration $(A: 0.031-0.619 \mathrm{M})$ and initial molar ratio ethanol/acid (MR; 0.257-2.443). After $48 \mathrm{~h}$ reaction time, the production of ethyl butyrate could be fitted to a surface described by a second-order polynomial model. A maximum ethyl butyrate concentration of $0.106 \mathrm{M}$, corresponding to $47 \%$ conversion into ester and a productivity of $2.21 \mu \mathrm{mole} / \mathrm{mL} \mathrm{h}$, is expected at initial reaction conditions of $T, A$ and $\mathrm{MR}$ of $33^{\circ} \mathrm{C}, 0.225 \mathrm{M}$ and 1.637, respectively. This maximum was experimentally confirmed.
\end{abstract}

(c) 2012 Elsevier Ltd. All rights reserved.

\section{Introduction}

Low molecular mass esters of carboxylic acids and alcohols play an important role in the food industry as flavour and aroma constituents (Liaquat and Apenten, 2000). An example is ethyl butyrate, an important component of many fruit flavours such as pineapple, passion fruit and strawberry (Rodriguez-Nogales et al., 2005).

The use of lipases (triacylglycerol acylhydrolase, EC 3.1.1.3) as an alternative to chemical catalysts, to catalyse esterification reactions aimed at the production of flavouring esters for food purposes, has been developed. Lipases are well known enzymes widely used in biocatalysis. Their ability to catalyse synthesis in non-aqueous media has made them extensively used to produce useful esters (Aragão et al., 2011; Dias et al., 1991; Karra-Châabouni et al., 2006; Krishna and Karanth, 2002; Liaquat and Apenten, 2000; Macedo et al., 2004; Mahapatra et al., 2009; Melo et al., 2005; Pires-Cabral et al., 2005a, 2005b, 2007, 2009, 2010; Rodriguez-Nogales et al., 2005; Tan et al., 2011). However, lipases must be used in immobilised forms,

\footnotetext{
Abbreviations: A, initial butyric acid concentration in the organic medium (M); CCRD, central composite rotatable design; Cmicro, initial substrate concentration in the microenvironment of the lipase (M); ESTER, ethyl butyrate concentration in the organic medium (M); EtOH, initial ethanol concentration in the organic medium (M); FHP 2002, foamable hydrophilic polyurethane pre-polymer "HYPOL FHP

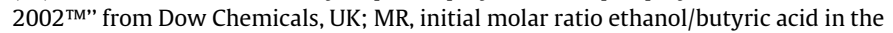
organic medium; $R^{2}$, coefficient of determination; $R_{\mathrm{adj}}^{2}$, adjusted coefficient of determination; RSM, response surface methodology; $U$, one lipase unit.

* Corresponding author at: Instituto Superior de Engenharia, Universidade do Algarve, Campus da Penha, 8005-139 Faro, Portugal. Tel.: +351 289 800100; fax: +351289888405.

E-mail addresses: ppcabral@sapo.pt, pcabral@ualg.pt (P. Pires-Cabral).
}

presenting both high catalytic activity and operational stability, in order to lower the costs of the biocatalyst in the process by reusing it in batch cycles or using it in continuous reactors. Lipase immobilisation in polyurethane foams has been reported by several authors (Awang et al., 2007; Dias et al., 1991; Kawamoto et al., 1987; Lejeune and Russell, 1996; Pires-Cabral et al., 2005a, 2005b, 2007, 2009, 2010). This technique consists of coupling entrapment with chemical binding during polymer synthesis. In previous studies, Candida rugosa lipase immobilised in hydrophilic polyurethane foams was successfully used as a catalyst for the following reactions: esterification of ethanol with butyric acid (Dias et al., 1991; Pires-Cabral et al., 2005a, 2005b, 2007, 2009, 2010), glycerolysis (Ferreira-Dias and Fonseca, 1993, 1995a, 1995b; Ferreira-Dias et al., 2003) and hydrolysis of olive oil and olive residue oils (Ferreira-Dias and Fonseca, 1995c; Ferreira-Dias et al., 1999).

In this study, a commercial Rhizopus oryzae lipase was immobilised in hydrophilic polyurethane foam and tested as a biocatalyst for the production of ethyl butyrate by esterification in $n$-hexane. Response surface methodology (RSM) was used to model and optimise the production of ethyl butyrate, as a function of temperature $(T)$, initial butyric acid concentration $(A)$ and initial molar ratio ethanol/butyric acid (MR).

\section{Materials}

\subsection{Enzyme}

The commercial powdered lipase from $R$. oryzae was kindly donated by Amano, U.K. This enzyme presents a minimum activity of 
$150 \mathrm{U} / \mathrm{mg}$ (one lipase unit, $\mathrm{U}$, releases one $\mu \mathrm{mol}$ of fatty acid from a triglyceride in one minute at $37^{\circ} \mathrm{C}$ ). In hydrolysis, it is highly active from $\mathrm{pH} 6.5$ to 7.5 (with an optimum $\mathrm{pH}$ of 7) and its optimum temperature is $40^{\circ} \mathrm{C}$.

\subsection{Polyurethane pre-polymer}

The polyurethane foam for lipase immobilisation was prepared from a toluene diisocyanate (TDI) pre-polymer ("Hypol FHP $2002^{\mathrm{TM}}$ ") kindly donated by Dow Chemical Company Limited, UK. This immobilisation support presents a porosity of about 0.64 (Dias et al., 1991) and a density of $884 \pm 25 \mathrm{~kg} / \mathrm{m}^{3}$, estimated from the weight and the respective final true volume of the foam (PiresCabral et al., 2007).

\subsection{Reagents}

Butyric acid, ethanol, ethyl butyrate, n-hexane and 4-methyl 2-penthanol (used as internal standard) were analytical grade and obtained from various commercial sources.

\section{Methods}

\subsection{Preparation of immobilised lipase}

Hydrophilic polyurethane foams were prepared by mixing the polyurethane pre-polymer ( $0.60 \mathrm{~g}$ of "Hypol FHP $\left.2002^{\mathrm{TM}}\right)$ with the aqueous phosphate buffer solution $\left(0.020 \mathrm{M} \mathrm{KH}_{2} \mathrm{PO}_{4}+0.027 \mathrm{M}\right.$ $\mathrm{Na}_{2} \mathrm{HPO}_{4}$; i.e., $0.023 \mathrm{M}, \mathrm{pH} 7.0$, ionic strength 0.1 ), containing $0.35 \mathrm{~g}$ of lipase powder, in a ratio of $1: 1(\mathrm{w} / \mathrm{w})$ (Ferreira-Dias et al., 1999). The amount of lipase used corresponds to the maximum load $(60 \%, \mathrm{w} / \mathrm{w})$ above which severe internal mass transfer limitations are encountered (Ferreira-Dias et al., 1999; Pires-Cabral et al., 2005a). After preparation, the "Hypol FHP 2002 ${ }^{\mathrm{TM} "}$ (or FHP 2002) foams containing immobilised lipase molecules were cut in cuboids $\left(\sim 0.07 \mathrm{~cm}^{3}\right)$ and used immediately. The hydrophilic FHP 2002 foam has an aquaphilicity value of 3.2 (Pires-Cabral et al., 2005a), which is an indicator of the affinity of the immobilisation support for water (Reslow et al., 1988).

\subsection{Time-course esterification experiments}

The immobilised lipase was immersed in $14 \mathrm{~cm}^{3} n$-hexane solution with an initial butyric acid concentration of $0.325 \mathrm{M}$ and a molar ratio ethanol/butyric acid of 1.350 . These conditions correspond to the central point of the experimental design followed for reaction modelling and optimisation (c.f. 3.3.). A load of $12 \%(w / v)$ of immobilised biocatalyst was used in the reaction medium. The esterification reaction was carried out at $30^{\circ} \mathrm{C}$ in a thermostatedcapped cylindrical glass vessel under magnetic stirring at $1400 \mathrm{rev} / \mathrm{min}$. In a time-course experiment, samples of $500 \mu \mathrm{L}$ of organic medium were withdrawn along $48 \mathrm{~h}$ reaction time and assayed for ethanol, butyric acid and ethyl butyrate content. These samples were added to equal volumes of $0.4 \mathrm{M}$ 4-methyl-2-penthanol (internal standard) in $n$-hexane, prior to the analysis by gas chromatography, as previously described (Pires-Cabral et al., 2005a). The initial esterification rate was calculated by linear regression on five data-points (time, ester concentrations). Volumetric productivity was calculated by the ratio between ethyl butyrate concentration and reaction time. The conversion into ethyl butyrate was defined as the ratio between ethyl butyrate concentration and the initial concentration of the limiting substrate in the organic medium.

\subsection{Experimental design experiments}

Response Surface Methodology (Gacula and Singh, 1984; Haaland, 1989) was used to model and optimise the esterification of ethanol with butyric acid, catalysed by the lipase from $R$. oryzae immobilised in polyurethane foam. The effect of the temperature $(T)$, initial butyric acid concentration $(A)$ and initial molar ratio ethanol/butyric acid (MR) on ester production (ESTER) was investigated. A total of 17 esterification experiments ( 3 central points, 4 factorial points and 4 stars points) were carried out following a central composite rotatable design (CCRD), where a five-level space filling design was used (Gacula and Singh, 1984; Montgomery, 2000). The standard deviation of the central point provides an independent estimate of the experimental error. The coded and decoded levels considered in the CCRD are presented in Table 1 and each independent variable was tested within the following ranges: T varied from 21.6 to $38.4{ }^{\circ} \mathrm{C}$, A from 0.031 to $0.619 \mathrm{M}$ and MR from 0.257 to 2.443 . The experiments were performed in a thermostated-capped cylindrical glass vessel under magnetic stirring at $1400 \mathrm{rev} / \mathrm{min}$, for $48 \mathrm{~h}$, as previously described (c.f. 3.2.).

\subsection{Microenvironmental substrate concentrations}

For each experiment of CCRD, the substrate concentrations in the microenvironment of the biocatalyst were estimated (Table 1) using the models previously established for a similar system, where the lipase from Candida rugosa immobilised in the same foam was used as a biocatalyst (Pires-Cabral et al., 2005a).

\subsection{Statistical Analysis}

For every experiment of CCRD, the ethyl butyrate concentration (ESTER) was analysed using the software "Statistica ${ }^{\mathrm{TM}}$ ", version 5, from Statsoft, Tulsa, USA.

Linear and quadratic effects of the independent variables and their linear interactions on ESTER were calculated and their significance was evaluated by analysis of variance. A four-dimensional surface, described by a second-order polynomial equation as a function of the three independent variables, was fitted to ESTER values. First- and second-order coefficients of this equation are usually unknown and, therefore, were estimated from the experimental data by using the statistical principle of least squares. The fit of the models was evaluated by the determination coefficients $\left(R^{2}\right)$ and adjusted $R^{2}\left(R_{\text {adj }}^{2}\right)$ (Gacula and Singh, 1984; Weisberg, $1985)$. The $R^{2}$ value provides a measure of how much of the variability in the observed response values can be explained by the experimental factors and their interactions. The $R_{\text {adj }}^{2}$ takes into account that the number of residual degrees of freedom in the polynomial regression changes as the order of the polynomial changes. $R_{\text {adj }}^{2}$ is an unbiased estimate of the coefficient of determination and is always smaller than $R^{2}$. In practice, $R^{2}$ should be at least 0.75 or greater; values above 0.90 are considered to be very good (Haaland, 1989).

\subsection{Validation of the esterification model}

To study the applicability of the model established by RSM to describe ester production, an esterification experiment was carried out in triplicate under the predicted optimised initial conditions. Along $48 \mathrm{~h}$ reaction time, samples of $500 \mu \mathrm{L}$ of organic medium were taken and assayed for substrates and product as previously described (c.f. 3.2.) and the obtained results were compared to the theoretical values predicted by the model. 
Table 1

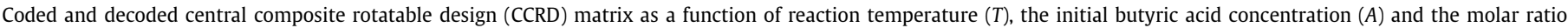

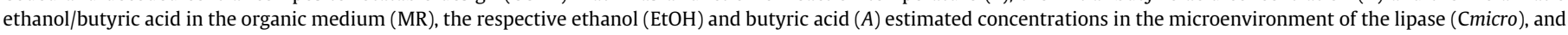
the experimental results of ethyl butyrate production (ESTER) after $48 \mathrm{~h}$ reaction time.

\begin{tabular}{|c|c|c|c|c|c|c|c|c|c|}
\hline \multirow[t]{2}{*}{ Experiment number } & \multicolumn{3}{|c|}{ Coded matrix } & \multicolumn{3}{|c|}{ Decoded matrix } & \multicolumn{2}{|c|}{ Cmicro (M) } & \multirow[t]{2}{*}{$\operatorname{ESTER}(\mathrm{M})$} \\
\hline & $T$ & $A$ & MR & $T\left({ }^{\circ} \mathrm{C}\right)$ & $A(\mathrm{M})$ & MR & EtOH & $A$ & \\
\hline 1 & -1 & -1 & -1 & 25 & 0.150 & 0.700 & 0.2475 & 0.4733 & 0.031 \\
\hline 2 & -1 & -1 & +1 & 25 & 0.150 & 2.000 & 0.8148 & 0.6165 & 0.112 \\
\hline 3 & -1 & +1 & -1 & 25 & 0.500 & 0.700 & 0.8247 & 1.1022 & 0.136 \\
\hline 4 & -1 & +1 & +1 & 25 & 0.500 & 2.000 & 3.0195 & 1.2455 & 0.010 \\
\hline 5 & +1 & -1 & -1 & 35 & 0.150 & 0.700 & 0.2475 & 0.4733 & 0.080 \\
\hline 6 & +1 & -1 & +1 & 35 & 0.150 & 2.000 & 0.8148 & 0.6165 & 0.115 \\
\hline 7 & +1 & +1 & -1 & 35 & 0.500 & 0.700 & 0.8247 & 1.1022 & 0.026 \\
\hline 8 & +1 & +1 & +1 & 35 & 0.500 & 2.000 & 3.0195 & 1.2455 & 0.009 \\
\hline 9 & $-\sqrt{ } 2$ & 0 & 0 & 21.59 & 0.325 & 1.350 & 1.3720 & 0.7730 & 0.164 \\
\hline 10 & $+\sqrt{ } 2$ & 0 & 0 & 38.41 & 0.325 & 1.350 & 1.3720 & 0.7730 & 0.016 \\
\hline 11 & 0 & $-\sqrt{ } 2$ & 0 & 30 & 0.031 & 1.350 & n.a. & 1.4964 & 0.013 \\
\hline 12 & 0 & $+\sqrt{ } 2$ & 0 & 30 & 0.619 & 1.350 & 2.3042 & 1.4964 & 0.009 \\
\hline 13 & 0 & 0 & $-\sqrt{ } 2$ & 30 & 0.325 & 0.257 & 0.0354 & 0.7013 & 0.071 \\
\hline 14 & 0 & 0 & $+\sqrt{ } 2$ & 30 & 0.325 & 2.443 & 2.3587 & 0.9422 & 0.008 \\
\hline 15 & 0 & 0 & 0 & 30 & 0.325 & 1.350 & 1.3720 & 0.7730 & 0.097 \\
\hline 16 & 0 & 0 & 0 & 30 & 0.325 & 1.350 & 1.3720 & 0.7730 & 0.095 \\
\hline 17 & 0 & 0 & 0 & 30 & 0.325 & 1.350 & 1.3720 & 0.7730 & 0.097 \\
\hline
\end{tabular}

n.a - not applicable.

\section{Results and discussion}

The time-course of the esterification reaction catalysed by commercial $R$. oryzae lipase immobilised in polyurethane foam, tested under the conditions of the central point of the experimental design performed for reaction modelling, is shown in Fig. 1. After $48 \mathrm{~h}$ reaction time, quasi-equilibrium was attained and the conversion into ethyl butyrate reached $32 \%$. The initial esterification rate and the volumetric productivity obtained were $148 \mu \mathrm{mol} / \mathrm{h} \mathrm{g} \mathrm{li-}$ pase and $2.13 \mu \mathrm{mol} / \mathrm{mL}$ h, respectively.

\subsection{Modelling ethyl butyrate production}

The ester production obtained in the 17 esterification experiments of the CCRD, catalysed by the commercial lipase from $R$. oryzae immobilised in polyurethane foam, is shown in Table 1 . To model the esterification reaction and optimise the temperature and initial medium composition, linear and quadratic effects of $T$, $A$ and MR and the respective linear interactions $(T \times A),(T \times \mathrm{MR})$ and $(A \times \mathrm{MR})$, on ethyl butyrate concentration were calculated (Table 2 ). For a given factor ( $T, A$ or MR), a positive or negative linear

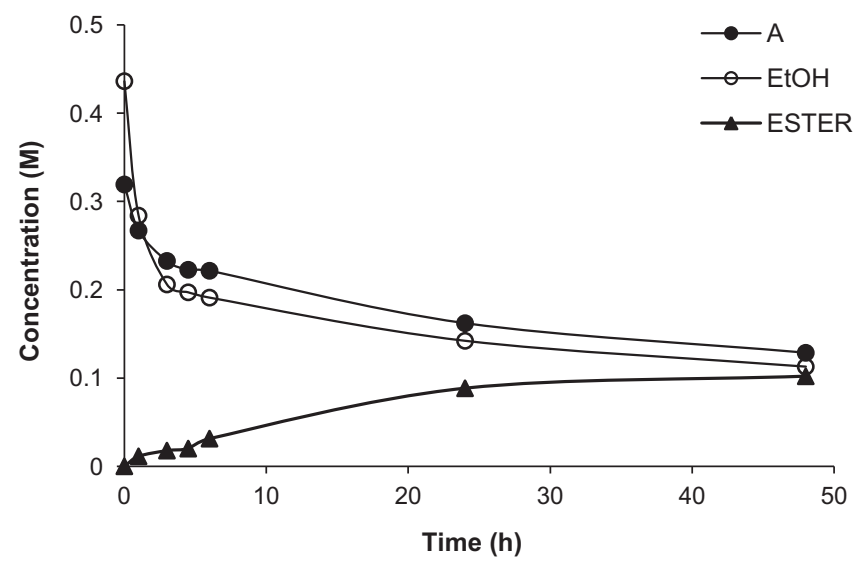

Fig. 1. Time-course of the production of ethyl butyrate (ESTER) by esterification of ethanol (EtOH) with butyric acid (A), catalysed by Rhyzopus orysae lipase immobilised in FHP 2002 foam, under the conditions of the central point of the experimental design.
Table 2

Linear and quadratic effects and respective $p$-levels (values between brackets) of the reaction temperature $(T)$, the initial butyric acid concentration $(A)$, the molar ratio ethanol/butyric acid (MR) and the respective interactions $(T \times A),(T \times \mathrm{MR})$ and $(A \times \mathrm{MR})$ on the production of ethyl butyrate (ESTER) catalysed by Rhizopus oryzae lipase immobilised in FHP 2002.

\begin{tabular}{ll}
\hline Factor & ESTER \\
\hline$T$ (linear term) & $-0.0521(0.071)$ \\
$T$ (quadratic term) & $0.003142(0.896)$ \\
$A$ (linear term) & $-0.02442(0.311)$ \\
$A$ (quadratic term) & $-0.04848(0.075)$ \\
MR (linear term) & $-0.03174(0.177)$ \\
MR (quadratic term) & $-0.02822(0.263)$ \\
$T \times A$ & $-0.04871(0.209)$ \\
$T \times$ MR & $0.050542(0.173)$ \\
$A \times$ MR & $-0.06261(0.061)$ \\
\hline
\end{tabular}

effect on a response (ESTER) indicates that an increase in the value of that factor is accompanied by a corresponding increase or reduction in the response, respectively. ANOVA results are presented in Table 3.

The observed experimental data (ESTER) could be fitted to a four-dimensional response surface described by a second-order polynomial equation, as a function of the factors with important effects on them. The significant effects $(p<0.05)$, and those having a confidence range smaller than the standard deviation, were included in the model equation (Haaland, 1989). Therefore, the quadratic effect of $T$ on ESTER was ignored.

This 4-dimensional response surface is presented in three three-dimensional response surfaces, as a function of two factors (temperature and butyric acid concentration or molar ratio and molar ratio and butyric acid concentration), keeping the third factor constant at its central value (i.e., $\mathrm{MR}=1.35$ or $A=0.325 \mathrm{M}$ or $T=30^{\circ} \mathrm{C}$, respectively) (Fig. 2). This convex response surface fitted to the production of ethyl butyrate (ESTER) showed a maximum in the experimental domain and is described by the following secondorder polynomial equation:

$$
\begin{aligned}
\text { ESTER }= & 0.0786-0.0064 T+1.681 A-0.8096 A^{2}-0.0745 M R \\
& -0.0347 M R^{2}-0.0284 T^{*} A+0.0078 T^{*} M R-0.2752 A^{*} M R
\end{aligned}
$$

The high values of both $R^{2}(0.802)$ and $R_{\mathrm{adj}}^{2}(0.604)$ show a good fit of the model to the experimental points. 
Table 3

Analysis of variance (ANOVA) for ethyl butyrate production catalysed by Rhizopus oryzae lipase immobilised in FHP 2002.

\begin{tabular}{lllll}
\hline $\begin{array}{l}\text { Source of } \\
\text { Variation }\end{array}$ & $\begin{array}{l}\text { Sum of } \\
\text { squares }\end{array}$ & $\begin{array}{l}\text { Degrees of } \\
\text { freedom }\end{array}$ & $\begin{array}{l}\text { Mean } \\
\text { squares }\end{array}$ & F-test \\
\hline $\begin{array}{l}T \text { (linear term) } \\
T \text { (quadratic }\end{array}$ & 0.006564 & 1 & 0.006564 & 6021.918 \\
$\quad 0.001719$ & 1 & 0.001719 & 1577.205 \\
$\quad$ term) & & & & \\
$A$ (linear term) & 0.007507 & 1 & 0.007507 & 6887.487 \\
$A$ (quadratic & 0.003256 & 1 & 0.003256 & 2986.973 \\
$\quad$ term) & & & & \\
MR (linear term) & 0.002634 & 1 & 0.002634 & 2416.954 \\
MR (quadratic & 0.00299 & 1 & 0.00299 & 2742.876 \\
$\quad$ term) & & & & \\
$T \times A$ & 0.003325 & 1 & 0.003325 & 3050.727 \\
$T \times$ MR & 0.007154 & 1 & 0.001692 & 6563.496 \\
$A \times$ MR & 0.010149 & 6 & $1.09 \mathrm{E}-06$ & 6021.918 \\
Lack of fit & $2.18 \mathrm{E}-06$ & 2 & & 1577.205 \\
$\begin{array}{l}\text { Pure error } \\
\text { Total }\end{array}$ & 0.05135 & 16 & & \\
\hline
\end{tabular}

Substrate concentrations in the microenvironment of $R$. oryzae lipase immobilised in FHP 2002 were also estimated (Table 1) using the models previously established for a similar system with a lipase from C. rugosa immobilised in the same polyurethane foam (PiresCabral et al., 2005a), assuming that similar interactions between the lipase and the immobilisation support occurred. However, the model equation proposed to estimate ethanol concentration (EtOH) in the microenvironment could not be used for the experiment 11 of CCRD $(A=0.031 \mathrm{M}$ and $\mathrm{EtOH}=0.042 \mathrm{M})$, because those models were established for a different range of initial concentrations of $A$ (0.078 to $0.572 \mathrm{M})$ and $\mathrm{EtOH}(0.105$ to $1.0 \mathrm{M})$.

For all the tested experiments, the substrate concentrations in the microenvironment were higher than those observed in the bulk, with the exception for experiment 13 of the CCRD $(A=0.325 \mathrm{M}$ and $\mathrm{EtOH}=0.084 \mathrm{M})$. Therefore, as previously observed (Pires-Cabral et al., 2005a), in the presence of high initial butyric acid concentration and an excess of ethanol, the migration of substrates for biocatalyst microenvironment is promoted due to the high hydrophilicity of the support.

Also, high concentration of substrates in microenvironment, particularly ethanol, in the experiments $4,8,12$ and 14 of CCDR (Table 1), conducted to low values of ethyl butyrate concentration, suggesting that ethanol has an inhibitory effect on the activity of $R$. oryzae immobilised lipase. Similar results were reported for $C$. rugosa lipase immobilised in the same foams, under high ethanol concentrations in the microenvironment (Pires-Cabral et al.,

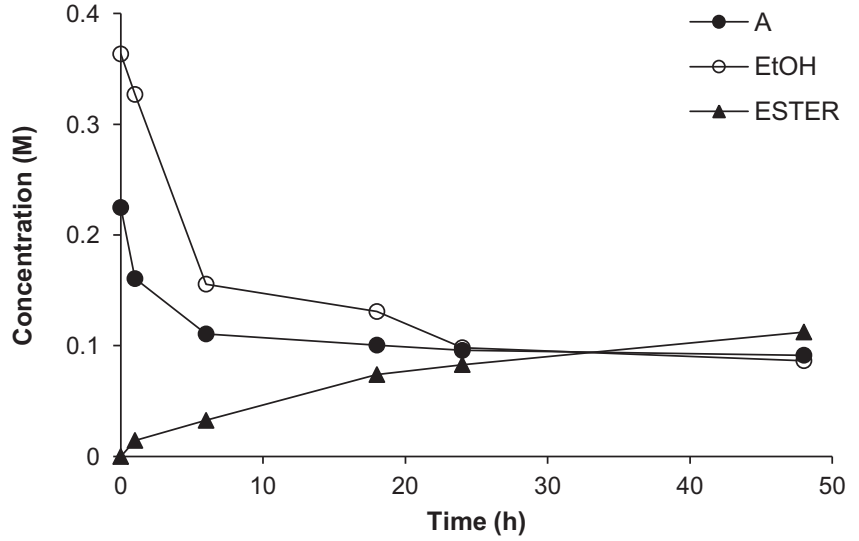

Fig. 3. Time-course of the production of ethyl butyrate (ESTER) by esterification of ethanol (EtOH) with butyric acid (A), catalysed by Rhyzopus orysae lipase immobilised in FHP 2002 foam, under the predicted initial optimised conditions.

2005a, 2007, 2010). Also, as suggested by Manjón et al. (1991), a decrease of biocatalyst activity may occur due to dehydration of the enzyme protein induced by the ethanol in the microenvironment of the enzyme.

At high microenvironment substrate concentrations, the increase of reaction temperature leads to lower values of ester production. Conversely, at low microenvironment substrate concentrations, a temperature increase conducts to high values of ethyl butyrate concentrations.

By partial differentiation of the polynomial equation for ESTER a maximum ester production of $0.106 \mathrm{M}$ is expected, after $48 \mathrm{~h}$ esterification reaction, at $32{ }^{\circ} \mathrm{C}$, when using $0.225 \mathrm{M}$ of $\mathrm{A}$ and 1.637 of MR. Also, under these predicted optimised conditions, substrate concentrations in the microenvironment of the biocatalyst were estimated, using the model equations previously established (Pires-Cabral et al., 2005a): $\mathrm{Cmicro}_{\mathrm{EtOH}}$ of $1.920 \mathrm{M}$ and $\mathrm{Cmicro}_{\mathrm{A}}$ equal to $0.644 \mathrm{M}$. The volumetric productivity and the conversion into ester, after $48 \mathrm{~h}$ esterification reaction, calculated with these predicted values are $2.21 \mu \mathrm{mol} / \mathrm{mLh}$ and $47 \%$, respectively.

In order to validate the model, an esterification experiment was carried out under the predicted initial optimised conditions for ester production. The time-course of the reaction is presented in Fig. 3. The obtained values were compared with the theoretical values predicted by the models. After $48 \mathrm{~h}$ reaction time, ethyl butyrate concentration was $0.112 \pm 0.002 \mathrm{M}$, corresponding to a
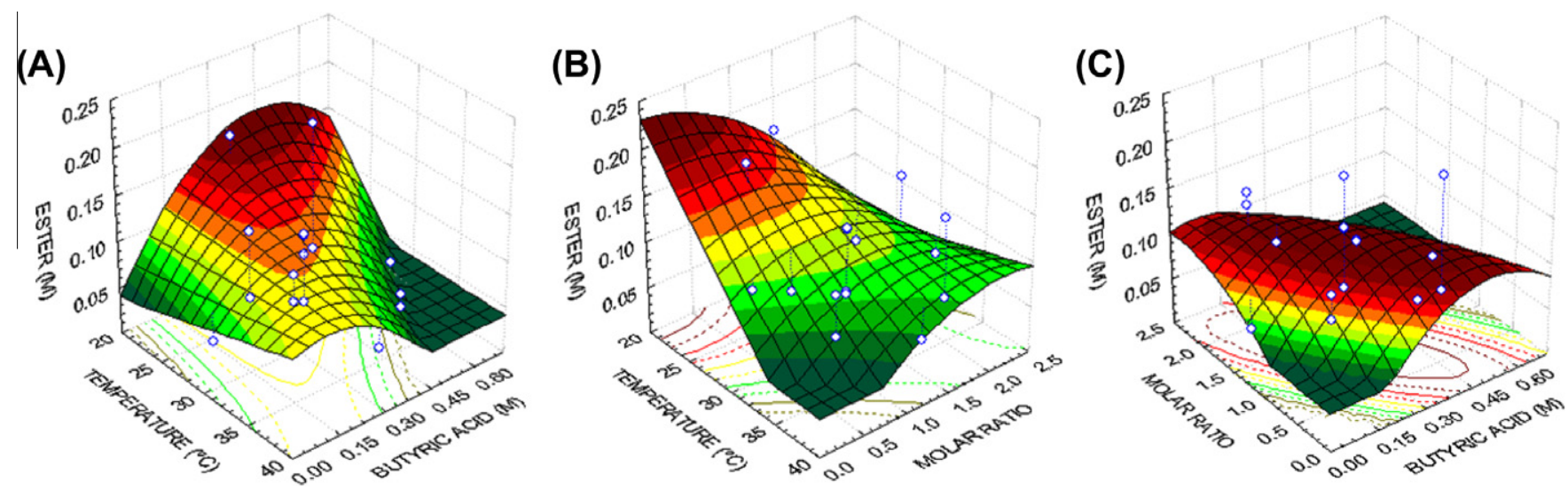

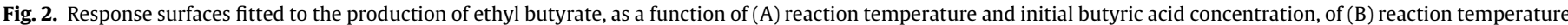

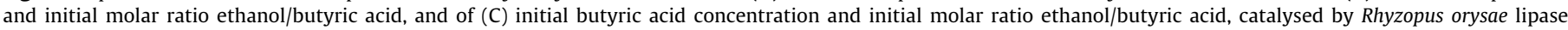
immobilised in FHP 2002 foam. 
Table 4

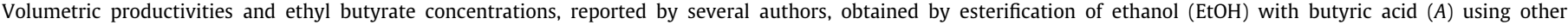
biocatalysts and under different reaction conditions and the corresponding results of the present work.

\begin{tabular}{|c|c|c|c|c|c|c|}
\hline Reference & Biocatalyst & Solvent & $\begin{array}{l}\text { Substrate } \\
\text { concentrations (M) }\end{array}$ & $\begin{array}{l}\text { Ester } \\
\text { concentration } \\
(\mathrm{M})\end{array}$ & $\begin{array}{l}\text { Ester } \\
\text { conversion } \\
(\%)\end{array}$ & $\begin{array}{l}\text { Volumetric productivity } \\
(\mu \mathrm{mol} / \mathrm{mL} \mathrm{h})\end{array}$ \\
\hline The present work & $\begin{array}{l}\text { R. oryzae lipase } \\
\text { immobilised in FHP } 2002\end{array}$ & n-hexane & $\begin{array}{l}0.225 \text { A; } 0.368 \\
\text { EtOH }\end{array}$ & 0.112 & 49.8 & 2.33 \\
\hline Aragão et al. (2011) & Lipozyme RM IM & n-heptane & $0.09 \mathrm{~A} ; 0.09 \mathrm{EtOH}$ & 0.079 & 87.8 & 26.4 \\
\hline Dave and Madamwar (2006) & $\begin{array}{l}\text { C. rugosa lipase } \\
\text { immobilised on silica-gel }\end{array}$ & $n$-hexane & $0.2 \mathrm{~A} ; 0.2 \mathrm{EtOH}$ & 0.190 & 95.0 & 1.98 \\
\hline Dias et al. (1991) & $\begin{array}{l}\text { C. rugosa lipase } \\
\text { immobilised in FHP } 2002\end{array}$ & n-hexane & $0.3 \mathrm{~A} ; 0.3 \mathrm{EtOH}$ & 0.210 & 70.0 & 8.58 \\
\hline Manjón et al. (1991) & $\begin{array}{l}\text { R. miehei lipase } \\
\text { immobilised in Celite }\end{array}$ & n-hexane & $0.1 \mathrm{~A} ; 0.2 \mathrm{EtOH}$ & 0.098 & 98.0 & 4.10 \\
\hline $\begin{array}{l}\text { Pires-Cabral et al. (2005a, 2005b, } \\
\text { 2007, 2009, 2010) }\end{array}$ & $\begin{array}{l}\text { C. rugosa lipase } \\
\text { immobilised in FHP } 2002\end{array}$ & n-hexane & $0.35 \mathrm{~A} ; 0.52 \mathrm{EtOH}$ & 0.243 & 69.5 & 10.1 \\
\hline Rodriguez-Nogales et al. (2005) & Novozym 435 & $n$-heptane & $0.04 \mathrm{~A} ; 0.52 \mathrm{EtOH}$ & 0.030 & 75.0 & 0.312 \\
\hline
\end{tabular}

conversion into ester of $50 \%$ and a volumetric productivity of $2.33 \mu \mathrm{mol} / \mathrm{mL} \mathrm{h}$. These values are similar to those predicted by the models, confirming the goodness of fit of the model to the experimental data, validating it.

\subsection{Comparison with other studies}

The esterification of ethanol with butyric acid catalysed by immobilised lipases was previously described (Aragão et al., 2011; Dave and Madamwar, 2006; Dias et al., 1991; Manjón et al., 1991; Pires-Cabral et al., 2005a, 2005b, 2007, 2009, 2010; Rodriguez-Nogales et al., 2005). The experimental conditions followed and the most important results obtained in these studies are presented in Table 4. When C. rugosa lipase was immobilised in FHP 2002 foam and used as a catalyst for the esterification of equimolar amounts of butyric acid and ethanol $(0.3 \mathrm{M})$, in $n$ hexane or $n$-heptane, final ester concentrations of $0.21 \mathrm{M}$ and $0.23 \mathrm{M}$, corresponding to volumetric productivities of $8.58 \mu \mathrm{mol} /$ $\mathrm{mLh}$ and $9.63 \mu \mathrm{mol} / \mathrm{mLh}$, were obtained, respectively (Dias et al., 1991). When the same biocatalyst was used at $30^{\circ} \mathrm{C}$ for ethyl butyrate production, using $0.35 \mathrm{M}$ of butyric acid and $0.529 \mathrm{M}$ of ethanol, $0.243 \mathrm{M}$ of ester was obtained after $24 \mathrm{~h}$ reaction time, corresponding to $69.5 \%$ of conversion into ester and a volumetric productivity of $10.1 \mu \mathrm{mol} / \mathrm{mL}$ h (Pires-Cabral et al., 2007). Dave and Madamwar (2006) used the same lipase immobilised on silica-gel as a catalyst for the esterification of initial equimolar substrate concentrations $(0.2 \mathrm{M})$, in $n$-hexane at $37^{\circ} \mathrm{C}$. Under these conditions, $0.19 \mathrm{M}$ of ethyl butyrate was obtained after $96 \mathrm{~h}$ reaction time (volumetric productivity of $1.98 \mu \mathrm{mol} / \mathrm{mL} \mathrm{h}$ ). Using RSM, Rodriguez-Nogales et al. (2005) predicted a maximum conversion to ethyl butyrate of $72.9 \%$, corresponding to $0.03 \mathrm{M}$ ester production, upon $96 \mathrm{~h}$ esterification reaction, at $34^{\circ} \mathrm{C}$ in $n$-heptane $(0.312 \mu \mathrm{mol} / \mathrm{mL} \mathrm{h})$, when a commercial immobilised preparation of Candida antarctica (Novozym 435, Novozymes, Denmark) was used with initial equimolar substrate concentrations of $0.04 \mathrm{M}$. When Rhizomucor miehei lipase immobilised in Celite was used to catalyse the esterification of $0.2 \mathrm{M}$ of ethanol with $0.1 \mathrm{M}$ of butyric acid in $n$-hexane, $98 \%$ conversion into ester was achieved, corresponding to a volumetric productivity of $4.1 \mu \mathrm{mol} / \mathrm{mL} \mathrm{h}$ (Manjón et al., 1991). Aragão et al. (2011) obtained around 88\% conversion into ethyl butyrate after $3 \mathrm{~h}$ reaction time $(26.4 \mu \mathrm{mol} /$ $\mathrm{mLh}$ ), with the commercial immobilised lipase from $R$. miehei (Lipozyme RM IM, Novozymes, Denmark). Esterification reaction was carried out at $45^{\circ} \mathrm{C}$ with an enzyme concentration of $7.7 \mathrm{~g} / \mathrm{L}$ in $n$-heptane and initial equimolar substrate concentrations of $0.09 \mathrm{M}$.
In the present study, the ethyl butyrate volumetric productivity obtained under optimised conditions is higher than the values reported by Rodriguez-Nogales et al. (2005) and by Dave and Madamwar (2006) but considerably lower than the values attained with C. rugosa lipase immobilised in polyurethane (Dias et al., 1991; Pires-Cabral et al., 2007) or with the commercial immobilised lipase from R. miehei, Lipozyme RM IM (Aragão et al., 2011). In a forthcoming work, polyurethane foams with lower hydrophilicity will be tested as supports for $R$. oryzae lipase in order to avoid substrate inhibitory concentrations in the microenvironment and promote ester production.

\section{Conclusions}

The present study shows that (i) the $R$. oryzae lipase immobilised in polyurethane foams can be used as a biocatalyst for the production of ethyl butyrate, (ii) the optimal reaction conditions for ethyl butyrate production may be achieved through the use of response surface models and that, (iii) in optimisation, special attention must be given to the inhibitory effect of ethanol on this lipase.

\section{References}

Aragão, V.C., Porto, M.R.A., Burkert, C.A.V., Kalil, S.J., Burkert, J.F.M., 2011. Response surface methodology approach for the synthesis of ethyl butyrate. Food Technology Biotechnology 49 (1), 103-110.

Awang, R., Ghazuli, M.R., Basri, M., 2007. Immobilization of lipase from Candida Rugosa on palm-based polyurethane foam as a support material. American Journal of Biochemistry and Biotechnology 3 (3), 163-166.

Dave, R., Madamwar, D., 2006. Esterification in organic solvents by silica-gel immobilized Candida rugosa lipase. In: Larroche, C., Pandey, A., Dussap, C.G. (Eds.), Current Topics on Bioprocesses in Food Industry. Asiatech Publishers Inc., New Deli, pp. 70-80.

Dias, S.F., Vilas-Boas, L., Cabral, J.M.S., Fonseca, M.M.R., 1991. Production of ethyl butyrate by Candida rugosa lipase immobilized in polyurethane. Biocatalysis 5 , $21-34$.

Ferreira-Dias, S., Fonseca, M.M.R., 1993. Enzymatic glycerolysis of olive oil: a reactional system with major analytical problems. Biotechnology Techniques 7, 447-452.

Ferreira-Dias, S., Fonseca, M.M.R., 1995a. Production of monoglycerides by glycerolysis of olive oil with immobilized lipases: effect of the water activity. Bioprocess Engineering 12, 327-337.

Ferreira-Dias, S., Fonseca, M.M.R., 1995b. Glycerolysis of olive oil: batch operational stability of Candida rugosa lipase immobilized in hydrophilic polyurethane foams. Bioprocess Engineering 13, 311-315.

Ferreira-Dias, S., Fonseca, M.M.R., 1995c. The effect of substrate hydrophobicity on the kinetic behaviour of immobilized Candida rugosa lipase. Biocatalysis and Biotransformation 13, 99-110.

Ferreira-Dias, S., Correia, A.C., Baptista, F.O., 1999. Activity and batch operational stability of Candida rugosa lipase immobilized in different hydrophilic polyurethane foams during hydrolysis in a biphasic medium. Bioprocess Engineering 21, 517-524. 
Ferreira-Dias, S., Correia, A.C., da Fonseca, M.M.R., 2003. Response surface modeling of glycerolysis catalyzed by Candida rugosa lipase immobilized in different polyurethane foams for the production of partial glycerides. Journal of Molecular Catalysis B: Enzymatic 21, 71-80.

Gacula Jr., M.C. \& Singh, J., 1984. Response surface designs and analysis. In: (Ed.), Statistical Methods in Food and consumer research. Food Science and Technology, A Series of Monographs, Academic Press, p. 214.

Haaland, P.D., 1989. Experimental Design in Biotechnology, Statistics: Textbooks and Monographs. In: D.B. Owen (Ed.), Marcel Dekker Inc., New York and Basel, p. 258.

Karra-Châabouni, M., Ghamgui, H., Bezzine, S., Rekik, A., Gargouri, Y., 2006. Production of flavour esters by immobilized Staphylococcus simulans lipase in a solvent-free system. Process Biochemistry 41, 1692-1698.

Kawamoto, T., Sonomoto, K., Tanaka, A., 1987. Esterification in organic solvents: selection of hydrolases and effects of reaction conditions. Biocatalysis 1,137145.

Krishna, S.H., Karanth, N.G., 2002. Lipases and lipase-catalyzed esterification reactions in nonaqueous media. Catalysis Reviews 44 (4), 499-591.

LeJeune, K.E., Russell, A.J., 1996. Covalent binding of a nerve agent hydrolyzing enzyme within polyurethane foams. Biotechnology and Bioengineering 5, 450457.

Liaquat, M., Apenten, R.K.O., 2000. Synthesis of low molecular weight flavour esters using plant seedling lipases in organic media. Journal of Food Science 65, 295299.

Macedo, G.A., Pastore, G.M., Rodrigues, M.I., 2004. Optimising the synthesis of isoamyl butyrate using Rhizopus sp. lipase with a central composite rotatable design. Process Biochemistry 39, 687-693.

Mahapatra, P., Kumari, A., Garlapati, V.K., Banerjee, R., Nag, A., 2009. Enzymatic synthesis of fruit flavor esters by immobilized lipase from Rhizopus oligosporus optimized with response surface methodology. Journal of Molecular Catalysis B: Enzymatic 60, 57-63.

Manjón, A., Iborra, J.L., Arocas, A., 1991. Short-chain flavour ester synthesis by immobilized lipase in organic media. Biotechnology Letter 13 (5), 339-344.
Melo, L.L.M.M., Pastore, G.M., Macedo, G.A., 2005. Optimized synthesis of citronelly flavour esters using freeand immobilized lipase from Rhizopus sp. Process Biochemistry 40, 3181-3185.

Montgomery, D.C., 2000. Design and Analysis of Experiments. Wiley, New York, 224-228.

Pires-Cabral, P., da Fonseca, M.M.R., Ferreira-Dias, S., 2005a. Modelling the microenvironment of a lipase immobilised in polyurethane foams. Biocatalysis and Biotransformation 23, 363-373.

Pires-Cabral, P., Dubreucq, E., da Fonseca, M.M.R., Ferreira-Dias, S., 2005b. Partitioning of water in organic systems with lipase immobilized in polyurethane foams. Biochemical Engineering Journal 26, 29-37.

Pires-Cabral, P., da Fonseca, M.M.R., Ferreira-Dias, S., 2007. Modelling the production of ethyl butyrate catalised by Candida rugosa lipase immobilised in polyurethane foams. Biochemical Engineering Journal 33, 148-158.

Pires-Cabral, P., da Fonseca, M.M.R., Ferreira-Dias, S., 2009. Synthesis of ethy butyrate in organic media catalyzed by Candida rugosa lipase immobilized in polyurethane foams: a kinetic study. Biochemical Engineering Journal 43 (3), 327-332.

Pires-Cabral, P., da Fonseca, M.M.R., Ferreira-Dias, S., 2010. Esterification activity and operational stability of Candida rugosa lipase immobilized in polyurethane foams in the production of ethyl butyrate. Biochemical Engineering Journal 48 (2), 246-252.

Reslow, M., Adlercreutz, P., Mattiasson, B., 1988. On the importance of the support material for bioorganic synthesis. Influence of water partition between solvent, enzyme and solid support in water-poor reaction media. European Journal of Biochemistry 172, 573-578.

Rodriguez-Nogales, J.M., Roura, E., Contreras, E., 2005. Biosynthesis of ethyl butyrate using immobilized lipase: a statistical approach. Process Biochemistry 40, 6368

Tan, H.S.G., Yu, B., Curran, P., Liu, S.Q., 2011. Lipase-catalysed synthesis of natural aroma-active 2-phenylethyl esters in coconut cream. Food Chemistry 124 80-84.

Weisberg, S., 1985. Applied Linear Regression, John Wiley \& Sons, 217-218 